\title{
Ki-67 Expression in CRC Lymph Node Metastasis Does Not Predict Survival
}

\author{
Sandra F. Martins, ${ }^{1,2,3}$ Ricardo Amorim, ${ }^{1,2}$ Sílvia Coelho Mota, ${ }^{1}$ Luís Costa, \\ Fernando Pardal, ${ }^{4}$ Mesquita Rodrigues, ${ }^{5}$ and Adhemar Longatto-Filho ${ }^{1,2,6,7}$ \\ ${ }^{1}$ Life and Health Sciences Research Institute (ICVS), School of Health Sciences, University of Minho, Campus of Gualtar, \\ 4710-057 Braga, Portugal \\ ${ }^{2}$ ICVS/3B's-PT Government Associate Laboratory, Braga/Guimarães, Campus of Gualtar, 4710-057 Braga, Portugal \\ ${ }^{3}$ Surgery Department, Hospitalar Center Trás-os-Montes e Alto Douro, Unidade Hospitalar de Chaves, \\ Avenida Dr. Francisco Sá Carneiro, 5400-279 Chaves, Portugal \\ ${ }^{4}$ Pathology Department, Braga Hospital, Sete Fontes, São Victor, 4710-243 Braga, Portugal \\ ${ }^{5}$ Coloproctology Unit, Braga Hospital, Sete Fontes, São Victor, 4710-243 Braga, Portugal \\ ${ }^{6}$ Laboratory of Medical Investigation (LIM) 14, Faculty of Medicine, University of Sao Paulo, 01246-903 São Paulo, SP, Brazil \\ ${ }^{7}$ Molecular Oncology Research Centre, 14784-400 Barretos, SP, Brazil \\ Correspondence should be addressed to Adhemar Longatto-Filho; longatto@ecsaude.uminho.pt
}

Received 4 December 2014; Accepted 2 February 2015

Academic Editor: Konstantinos Arnaoutakis

Copyright (C) 2015 Sandra F. Martins et al. This is an open access article distributed under the Creative Commons Attribution License, which permits unrestricted use, distribution, and reproduction in any medium, provided the original work is properly cited.

Colorectal cancer is one of the most common malignancies and a leading cause of cancer death worldwide. Molecular markers may improve clinicopathologic staging and provide a basis to guide novel therapeutic strategies which target specific tumourassociated molecules according to individual tumour biology; however, so far, no ideal molecular marker has been found to predict disease progression. We tested Ki-67 proliferation marker in primary and lymph node metastasis of CRC. We observed a statistical significant difference between the positive rates of neoplastic cells positively stained by Ki-67 in both sites, with remarkable increased number of Ki-67 positive cells in primary tumor cells compared to cancer cells that invaded lymph nodes. We can speculate that the metastatic CRC in lymph node can be more resistant to the drugs that target cellular division.

\section{Introduction}

Colorectal cancer (CRC) is one of the most common malignancies and a leading cause of cancer death worldwide [1-5]. European countries rank the highest in the global statistics, in terms of both CRC incidence and mortality $[4,6]$, although in recent years, a decline in CRC mortality rates has been observed, mostly due to improvement in earlier diagnosis and treatment $[4,7]$.

In Portugal, official data revealed that CRC is the second most common type of cancer, in both men and women, and in 2008 it was responsible for $18.7 \%$ and $15.1 \%$, respectively, of all cancer in Portugal [8]. Regarding mortality, unlike European data [9], there was an average increase of 3\% from 2000 to
2005 [10] and in 2012 incidence and mortality rates are higher than European rates [11].

For CRC, the pathologic clinical stage is currently the single most important prognostic factor $[1-4,12,13]$, correlating with long-term survival [4, 14-17], although it does not fully predict individual clinical outcome [4, 17-19]. This is particularly true for those tumours with intermediate stage disease (T3-T4N0M0) [19], where one-third of patients with tumour-free lymph nodes have recurrences, and therefore adjuvant chemotherapy may be beneficial [20]. In this group, carcinoma cells are not detected in lymph nodes by conventional staging methods in $24 \%$ of patients. So, lymphatic staging is essential to improve treatment of these patients, indeed one-third of the patients submitted to curative intent 
surgery die of local and/or distant tumour recurrence $[4,15]$. Abdominal lymph nodes (38\%) are the second most frequent site of metastasis (38\%), just after liver, that is, the organ most frequently involved (38-60\% of cases) and followed by lung $(38 \%)$ and peritoneum $(28 \%)[4,13]$.

A common feature of all cancers is the imbalance that exists between the proliferative activity and cell death; therefore, the evaluation of cell proliferation rate may be interesting in the study and characterization of tumours [21]. Some molecules, such as the Ki-67 protein, permit this assessment and are used as markers of proliferation because Ki67 expression is dependent of cell division rate; thus, overexpression of these markers may suggest a disruption in the proliferation mechanism leading to the appearance of tumours [21].

Ki-67 protein, when used to evaluate the percentage of dividing cells, allows us to determine neoplastic growth [21] and has been documented to correlate with neoplastic progression [22] showing different levels of expression between normal mucosa, adenoma, and adenocarcinoma [23], verifying a progressive increasing of positive Ki-67 expression from the first (normal mucosa) to the last part of the tissue (adenocarcinoma) [22, 24, 25].

Other studies correlate Ki-67 with the degree of malignancy, tumour invasiveness $[25,26]$, metastatic potential [21], patient survival, and the risk of relapse [27, 28]. Thus, a high Ki-67 expression in tumour cells is assumed to correlate with a poor tumour differentiation $[24,26]$ and an increased infiltration of the bowel wall (pT) [26]. Micev et al. [29] demonstrated that there is an association between Ki-67 expression and a less effective response in patients undergoing chemotherapy.

Other correlations with clinical and pathological data were also investigated and correlation was detected between a high expression of this protein and the following variables: patient's age [25], tumour size [30], tumour localization [28], dysplasia degree [30], the presence of lymph node metastasis [22, 25, 28], and TNM [25] and Dukes [28] classification. Thus, the younger is the patient, the greater is the cellular proliferation and the lower is the degree of differentiation; with increasing malignancy a increased frequency of invasion and metastasis are observed and thus poorer prognosis [25].

In $\mathrm{CRC}$, the analysis of colon adenomas has shown a different pattern for Ki-67 expression between normal tissue, adenomas, and adenocarcinomas, being limited to the crypts in normal tissue and expressed both in the crypts and in the surface epithelium in adenomatous polyps (tubular, villous) [31] and distributed homogeneously in adenocarcinoma [32]. Nussrat et al. [30] also observed an increase in Ki-67 rates being associated with the growth and rise of dysplasia in adenomas.

Studies on CRC indicated $\mathrm{Ki}-67$ as a prognostic marker as the survival rate for patients with high expression of $\mathrm{Ki}-67$ is significantly lower compared to those with low expression [25, 33-35] and a predictor of CRC recurrence [36]. Also significant associations were found between higher index of Ki67 and increased tumour penetration $[35,37]$, the presence of lymph node [22,35] and distant [35] metastasis, advanced TNM stage $[32,35]$, highest degree of differentiation, and subtypes of adenocarcinoma other than mucinous [38].
However, not all studies are in agreement, and no correlations were observed with patient age, gender, tumour location $[22,30,33,39]$, and the type of adenoma [30] for some of them. Allegra et al. [40] described inverse associations, with a lower rate of $\mathrm{Ki}-67$ to be associated with greater recurrence and worse overall survival and Jansson and Sun [39] did not find any associations between index Ki-67 and clinicopathological data or prognosis.

Regarding the use of Ki-67 in CRC lymph node metastasis, no information is available, and the only similar study found compares Ki-67 index in primary tumour with peritoneal metastasis and had observed a lower proliferative index in metastasis compared with the primary tumour [41]. However, in other types of cancer, in particular breast cancer, a higher Ki-67 index was found in lymph node metastasis than in primary tumours [42-44], suggesting greater aggressiveness of these [42] and that the use of Ki-67 in lymph node metastasis may be important in selecting the appropriate treatment for certain subgroups of patients [45].

Therefore, given the limited information concerning Ki67 index in CRC lymph nodes metastasis and primary tumour, this study becomes relevant to determine Ki-67 index in the primary tumour and, respectively, lymph nodes metastasis whilst trying to establish correlations with this and clinicopathological data and the patient's prognosis.

\section{Materials and Methods}

2.1. CRC Tumour Series. Tissue samples and data from 672 patients treated in Hospital de Braga, Portugal, between January 1, 2005, and January 1, 2010, with CRC diagnosis were collected prospectively. Tumour localization was recorded and classified as colon and rectum (between anal verge and $15 \mathrm{~cm}$ at rigid rectoscopy).

The histological type of CRC was classified by two experienced pathologists and tumour staging was graded according to the TNM classification, sixth edition [46]. Tissue microarrays (TMAs) were constructed with the CRC series of formalin-fixed, paraffin-embedded tissues and analyzed by immunohistochemistry. Prior to tumour construction, hematoxylin and eosin sections were reviewed to select representative areas of the tumour and normal-adjacent tissue. Each case was represented in the TMA by at least two cores of $0.6 \mathrm{~mm}$.

2.2. Lymph Node Metastasis Series. From the same series of colorectal cancer, patients with the diagnosis of CRC lymph node metastasis were selected and a series of 210 patients were also collected.

Additionally, 35 patients, with the diagnosis of CRC but without lymph node metastasis, were also selected for control of protein lymph node expression (stages T1 and T2/N0).

TMAs were constructed with the lymph node metastasis series of formalin-fixed, paraffin-embedded tissues and analyzed by immunohistochemistry. Each case was represented in the TMA by at least two cores of $0.6 \mathrm{~mm}$.

The study protocol was approved by the Ethics Committee of Hospital de Braga and ICVS. 


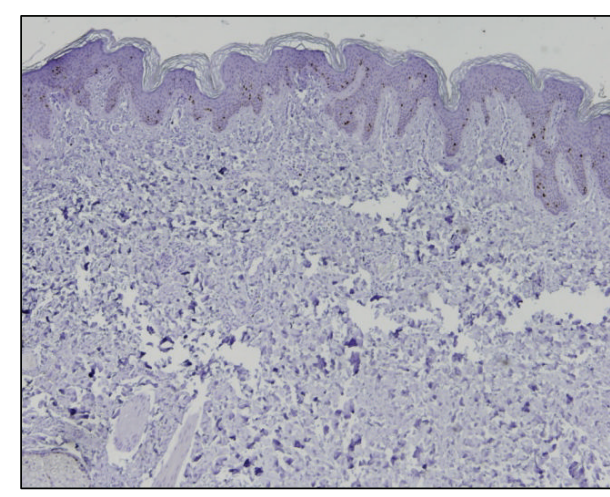

(a)



(b)

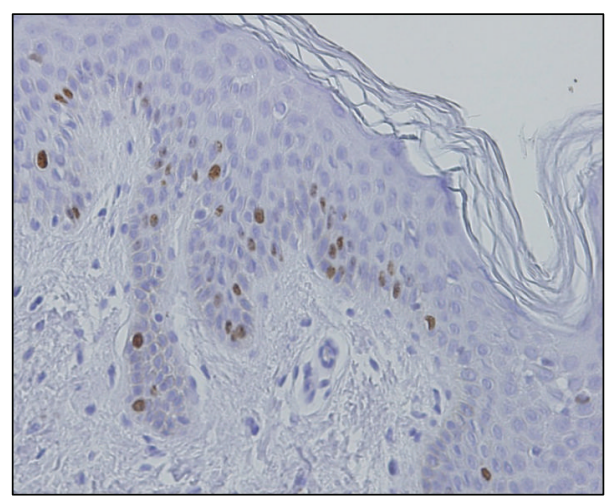

(c)

FIGURE 1: Immunohistochemical expression of Ki-67 in samples of skin: (a) original magnification $\times 40$; (b) original magnification $\times 100$; (c) original magnification $\times 200$.

TABLE 1: Detailed aspects of the immunohistochemical procedure used to visualise the Ki-67.

\begin{tabular}{|c|c|c|c|c|c|c|}
\hline \multirow{2}{*}{ Protein marker } & \multirow{2}{*}{ Antigen retrieval } & \multirow{2}{*}{$\begin{array}{c}\text { Peroxidase } \\
\text { inactivation }\end{array}$} & \multirow{2}{*}{ Detection system } & \multicolumn{3}{|c|}{ Antibody } \\
\hline & & & & Company & Dilution & Incubation period \\
\hline Ki-67 & $\begin{array}{c}\text { Citrate Buffer } \\
0.01 \mathrm{M} \mathrm{pH}=6.0\end{array}$ & $\begin{array}{c}3 \% \mathrm{H}_{2} \mathrm{O}_{2} \text { in } \\
\text { methanol, } 10 \mathrm{~min} .\end{array}$ & $\begin{array}{c}\text { RTU Vectastain } \\
\text { ABC elite Reagent }\end{array}$ & GenNova & $1: 200$ & Overnight \\
\hline
\end{tabular}

2.3. Immunohistochemistry. CRC and lymph nodes TMAs protein expression was evaluated by immunohistochemistry. Detailed information is given in Table 1. After the immunohistochemical procedure, the slides were evaluated and then photographed under a microscope.

For positive control of the expression of Ki-67 a sample of the skin was used (Figure 1).

2.4. Immunohistochemical Evaluation. The percentage of immunoreactive cells was determined (which was named the Ki-67 index), counting a total of 100 cells per section at $\times 20$ magnification, and each one was assigned a score from 0 to 3 , as previously described by Pinheiro et al. [47].

Immunoreaction final score was defined as the sum of both parameters and grouped as negative (0-1) and positive $(\geq 2)$. Evaluation of protein expression was performed by blind analysis by two observers and discordant cases were discussed in a double-head microscope in order to determine a final score.
2.5. Statistical Analysis. All data were analyzed using the Statistical Package for the Social Sciences, version 19.0 (SPSS Inc., Chicago, IL, USA). All comparisons were examined for statistical significance using Pearson's chi-square $\left(\chi^{2}\right)$ test and Fisher's exact test (when $n<5$ ), with the threshold for significance $P<0.05$. Survival curves were determined for overall survival by the Kaplan-Meier method and log-rank test.

Expression differences between lymph node metastasis and primary CRC were tested with McNemar test, with the threshold for significance $P<0.05$.

\section{Results}

3.1. Ki-67 Expressions in CRC Samples. A total of 672 samples were organized into TMAs, including tumour and normal adjacent epithelium $\left(\mathrm{NA}^{\mathrm{E}}\right)$. Sections were evaluated for immunoexpression and the obtained results are given in Table 2, which summarizes the frequency of Ki-67 expression in tumour cells and $\mathrm{NA}^{\mathrm{E}}$. 
TABLE 2: Pattern of protein staining in tumour versus normal adjacent epithelium.

\begin{tabular}{lccc}
\hline $\begin{array}{l}\text { Protein marker } \\
\text { Ki-67 }\end{array}$ & $n$ & $\begin{array}{c}\text { Immunoreaction } \\
\text { Positive } n(\%)\end{array}$ & $P$ \\
\hline CCR & & & \\
$\quad$ NA & 140 & $34(24.3)$ & $<\mathbf{0 . 0 0 1}$ \\
$\quad$ Tumour & 506 & $345(68.2)$ & \\
Lymph node & & & \\
$\quad$ Normal & 2 & $2(100.0)$ & $0.502^{*}$ \\
$\quad$ Metastasis & 109 & $60(55.0)$ & \\
\hline
\end{tabular}

$\widehat{\mathrm{NA}^{\mathrm{E}} \text { : normal adjacent epithelium; } n \text { : total number of cases with and without }}$ expression of Ki-67; positive $n$ (\%): total number of cases with expression of $\mathrm{Ki}-67$ and respective percentage.

${ }^{*}$ Comparisons were examined for statistical significance using Fisher's exact test (when $n<5)$.

We observed that $68.2 \%(n=345)$ of the samples of tumour tissue were positive for Ki-67, as compared to $24.3 \%$ $(n=34)$ of samples of the samples of $\mathrm{NA}^{\mathrm{E}}$. Thus, it was concluded that the Ki-67 expression is significantly higher in tumour tissue $(P<0.05)$, such as is shown in Table 2 .

Figure 2 shows representative cases of positive staining for Ki-67 in tumour cells and in $\mathrm{NA}^{\mathrm{E}}$.

3.2. Associations between Ki-67 Expressions in CRC Tissues and Clinicopathological Data. The associations observed between the expression of Ki-67 in CRC and the clinicopathological data are described in Tables 3 and 4.

Analyzing the results in these tables, we found an association between the expression of Ki-67 and "tumour penetration" $(P=0.013)$ and "tumour differentiation" $(P=0.049)$.

For "tumour penetration," we observed a decreasing expression of Ki-67 from the pT1 (79.3\%) to pT3 (68.1\%) tumours and then a rise in expression for adenocarcinoma with invasion of other organs or structures (pT4) (73.1\%).

Regarding "tumour differentiation," we observed an increasing expression of Ki-67 from the well-differentiated to the undifferentiated tumours, namely, well differentiated $(64.6 \%)$, moderately differentiated $(70.2 \%)$, and poorly differentiated $(85.1 \%)$. Conversely, undifferentiated tumours showed lower expression of Ki-67 compared to the degree of differentiation mentioned above.

We did not find any statistically significant relationship between clinicopathological data and Ki-67 index in CRC for the remaining assessed data.

3.3. Overall Survival Curves according to Ki-67 Expressions in CRC Tissues. No statistically significant association was observed for Ki-67 expression in CRC tissues $(P=0.321$ for CRC, and $P=0.213$ and $P=0.874$ for colon cancer and rectal cancer evaluated separately, resp.), as observed in Figure 4.

Relatively to CRC, survival of patients that are negative for $\mathrm{Ki}-67$ is $65.6 \%$ with a medium of survival of $65.0 \pm 2.8$ months after diagnosis, while Ki-67 positive patients present a survival of $62.3 \%$ with a medium of survival of $62.1 \pm 2.1$ months after diagnosis, such as is shown in Table 5.
3.4. Ki-67 Expressions in Lymph Node Metastasis Samples. A total of 210 samples were organized into TMAs. Additionally 35 patients, with the diagnosis of CRC but without lymph node metastasis, were also selected for control of protein lymph node expression (stages T1 and T2 N0). Sections were evaluated for immunoexpression and the obtained results are given in Table 2, which summarizes the frequency of Ki67 expression in "normal" lymph nodes and lymph node metastasis.

We observed that $55.5 \%(n=60)$ of the samples of lymph node metastasis were positive for Ki-67, compared to $100 \%$ $(n=2)$ of samples of the samples of "normal" lymph nodes. No significant correlation was observed $(P=0.502)$, such as is shown in Table 2 and Figure 3.

3.5. Associations between Ki-67 Expressions in Lymph Node Metastasis and Clinicopathological Data. The associations observed between the expression of Ki-67 in lymph node metastasis of CRC and the clinicopathological data are described in Tables 3 and 4. Analyzing these tables, we did not find any statistically significant relationship between clinicopathological data and Ki-67 index in lymph node metastasis.

3.6. Overall Survival Curves according to Ki-67 Expressions in Lymph Node Metastasis. Relatively to overall survival, patients with negative Ki-67 index present a survival of $65.3 \%$ with a medium of survival of $63.4 \pm 5.2$ months after diagnosis, while Ki-67 index positive patients present a survival of $51.6 \%$ with a medium of survival of $50.0 \pm 4.6$ months after diagnosis, such as is shown in Table 5 .

No statistically significant association was observed for Ki-67 expression in CRC lymph node metastasis tissues $(P=$ 0.131 for CRC, $P=0.127$ and $P=0.809$ for colon cancer and rectal cancer evaluated separately, resp.); however, a tendency for the relationship between a positive $\mathrm{Ki}-67$ index and a lower overall survival was observed, such as is shown in Figure 5.

3.7. Comparing Ki-67 Index Expressions in Lymph Node Metastasis and Primary Tumour. Table 6 represents a comparison between Ki-67 index in the primary tumour and the respective lymph node metastasis. Analyzing this table, it appears that 12 of the cases with negative Ki-67 index in the primary tumour have positive index in lymph node metastasis and that 29 of those with positive index in the primary tumour have a negative index in lymph node metastasis, for a total of 41 discordant cases. This means that there is a significant difference $(P=0.012)$ between the index of Ki-67 in primary tumour and the respective lymph node metastasis. A smaller number of cases of positive Ki-67 index were also observed in lymph node metastasis $(n=61 ; 57.5 \%)$ than in the primary tumour $(n=78 ; 73.6 \%)$ as is schematized in Figure 6 .

\section{Discussion}

The mechanisms that culminate in CRC development, growth, and metastization are still not fully understood. 


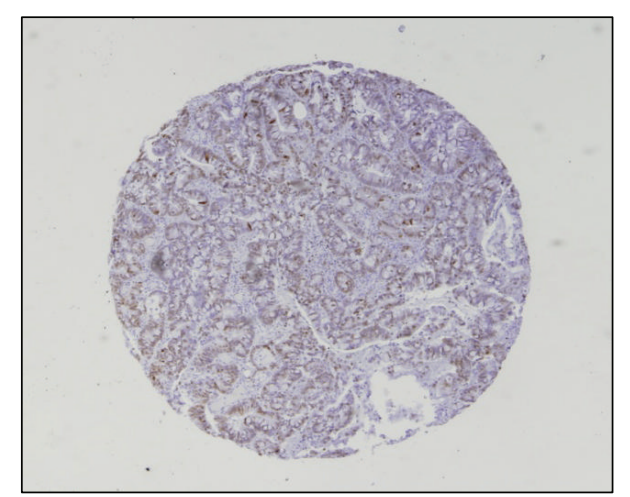

(a)

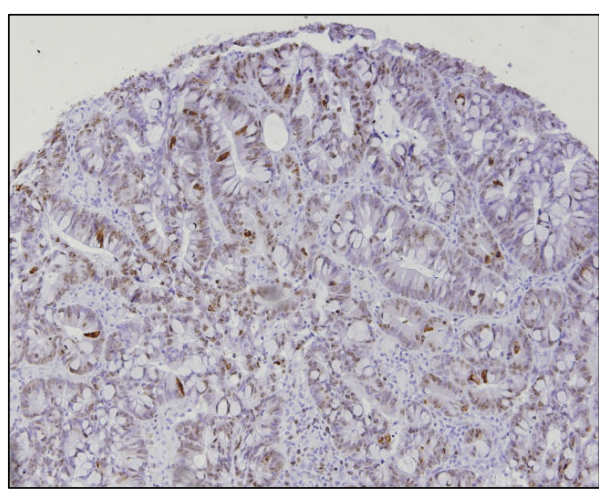

(b)

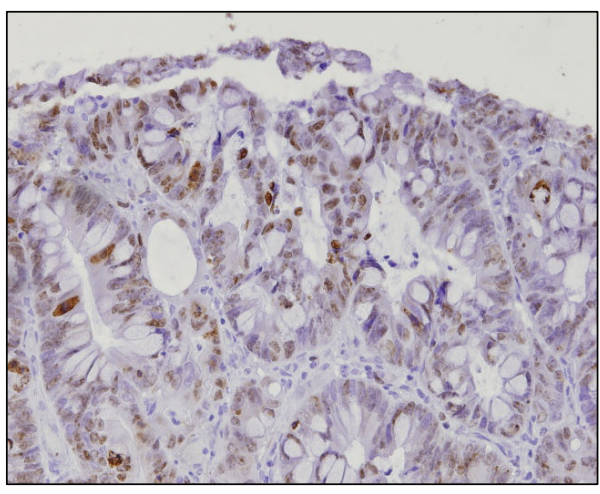

Tumours cells

(c)

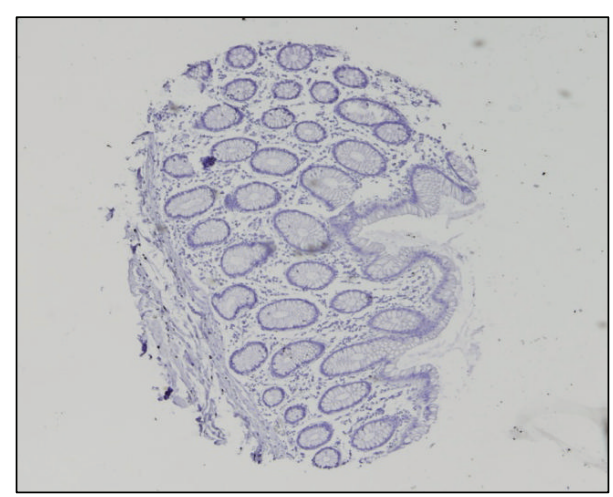

(d)

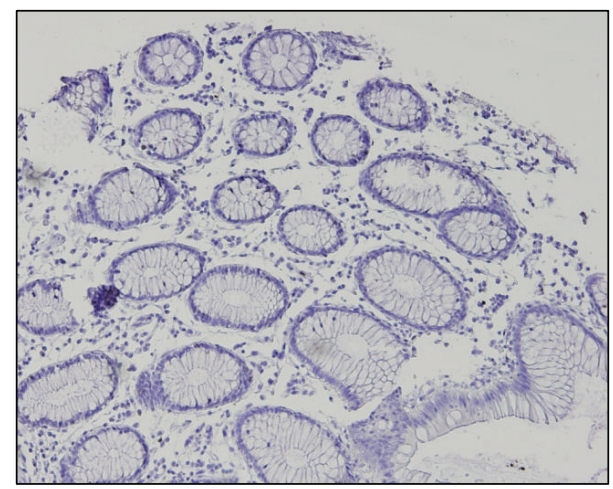

(e)



Adjacent normal epithelium

(f)

Figure 2: Immunohistochemical expression of Ki-67 in colorectal cancer samples: ((a) and (d)) original magnification $\times 40$; ((b) and (e)) original magnification $\times 100$; ((c) and (f)) original magnification $\times 200$.

However, common to all cancers are the loss of cellular differentiation and the imbalance between proliferation and cell death; these processes, involved in carcinogenesis, due to its significance, are increasingly being targeted for study.

Ki-67 protein has been widely used as a marker of tumour proliferation $[21,48,49]$, and several studies compare Ki-67 index with clinicopathological data and follow-up in CCR $[22,32,35-40]$. With regard to Ki-67 index in lymph node metastasis, as far as we know, this is the first study realized in CRC and, the more similar that we found in literature is the study of Yamauchi et al. [41], which compares Ki-67 index in primary CRC tumours with the respective nodules of peritoneal metastization.

In this study, we determine immunohistochemical expression of $\mathrm{Ki}-67$ protein in CRC samples and respective lymph node metastasis and intended to evaluate possible associations between these expressions and several clinicopathological parameters and patient survival. Further comparison was performed between $\mathrm{Ki}-67$ index in CRC and respective lymph nodes metastasis.

Regarding Ki-67 expression in CRC samples and $\mathrm{NA}^{\mathrm{E}}$ we observed a significant expression of Ki-67 in the first over 
TABLE 3: Assessment of correlation between Ki-67 expression and clinical data.

\begin{tabular}{|c|c|c|c|c|c|c|}
\hline & \multicolumn{3}{|c|}{$\mathrm{Ki}-67$ in CRC } & \multicolumn{3}{|c|}{ Ki-67 in lymph node metastasis } \\
\hline & $n$ & Positive $n(\%)$ & $P$ & $n$ & Positive $n(\%)$ & $P$ \\
\hline \multicolumn{7}{|l|}{ Gender } \\
\hline Male & 307 & $212(69.1)$ & \multirow{2}{*}{0.675} & 71 & $41(57.7)$ & \multirow{2}{*}{0.438} \\
\hline Female & 180 & $121(67.2)$ & & 38 & $19(50.0)$ & \\
\hline \multicolumn{7}{|l|}{ Age } \\
\hline$\leq 45$ & 23 & $14(60.9)$ & \multirow{2}{*}{0.491} & 7 & $4(57.1)$ & \multirow{2}{*}{$1.000^{\circ}$} \\
\hline$>45$ & 464 & $319(68.8)$ & & 102 & $56(54.9)$ & \\
\hline \multicolumn{7}{|l|}{ Presentation } \\
\hline Asymptomatic & 88 & $63(71.6)$ & \multirow{2}{*}{0.474} & 19 & $8(42.1)$ & \multirow{2}{*}{0.212} \\
\hline Symptomatic & 399 & $270(67.7)$ & & 90 & $52(57.8)$ & \\
\hline \multicolumn{7}{|l|}{ Localization } \\
\hline Colon & 353 & $240(68.0)$ & \multirow{2}{*}{0.764} & 90 & $50(55.5)$ & \multirow{2}{*}{0.84} \\
\hline Rectum & 134 & $93(69.4)$ & & 19 & $10(52.6)$ & \\
\hline \multicolumn{7}{|c|}{ Macroscopic cancer type } \\
\hline Polypoid & 253 & $171(67.6)$ & \multirow{5}{*}{0.178} & 45 & $20(44.4)$ & \multirow{5}{*}{0.37} \\
\hline Ulcerative & 111 & $76(68.5)$ & & 31 & $20(64.5)$ & \\
\hline Infiltrative & 38 & $22(57.9)$ & & 11 & $6(54.5)$ & \\
\hline Exophytic & 39 & $32(82.1)$ & & 12 & $7(58.3)$ & \\
\hline Vilosous & 2 & $2(100.0)$ & & 1 & $0(0)$ & \\
\hline \multicolumn{7}{|l|}{ CEA (ng/mL) } \\
\hline$\leq 10$ & 337 & $229(68.0)$ & \multirow{2}{*}{0.750} & 67 & $34(50.7)$ & \multirow{2}{*}{0.757} \\
\hline$>10$ & 73 & $51(69.1)$ & & 22 & $12(54.5)$ & \\
\hline
\end{tabular}

${ }^{*}$ Comparisons were examined for statistical significance using Fisher's exact test (when $n<5$ ).

the second $(P<0.001)$. These results were expected, since due to its role as a marker of cellular proliferation, a higher expression was expected in tumour tissue than in normal epithelium. These results were also demonstrated by Lin et al. [25].

The same analysis was made for lymph nodes metastasis and "normal" lymph nodes, but no significant correlation was observed $(P=0.502)$. Possible explanations are the fact that "normal" lymph nodes are not truly normal, but of patients with CRC without lymph nodes metastasis (T1 and T2/N0) so this is a bias to be considered since they may already be under the influence of the tumour environment. Another fact that may influence this result is the small size sample of the "normal" lymph node, so further studies need to be realized with bigger samples and normal lymph nodes for control.

When analyzing the correlation of Ki-67 expression in $\mathrm{CRC}$ with pathological data, we found an association between the expression of Ki-67 and "tumour penetration" $(P=0.013)$ and "tumour differentiation" $(P=0.049)$.

For "tumour penetration," we observed a decreasing expression of Ki-67 from the pT1 (79.3\%) to pT3 (68.1\%) tumours and then a rise in expression for adenocarcinoma with invasion of other organs or structures (pT4) (73.1\%).

The decreased expression of Ki-67 with the increasing tumour penetration is conflicting since we would expect an increase in expression with increasing tumour wall penetration, as is observed for pT4. But as the Ki-67 is only a marker of cellular proliferation, other factors may influence this outcome.
Regarding "tumour differentiation," we observed an increasing expression of Ki-67 from the well-differentiated to the undifferentiated tumours; conversely, undifferentiated tumours showed lower expression of Ki-67 compared to the degree of differentiation mentioned above.

As was observed by some authors $[38,50]$, the more undifferentiated is the tumour, the higher is the rate of cell proliferation and therefore Ki-67 index. This is not consistent with our findings; however, since the lower expression in undifferentiated tumours may be explained by the small size of this sample, further studies with larger series of undifferentiated tumours are necessary.

When analyzing the correlation of Ki-67 expression in lymph node metastasis with pathological data, any statistically significant relationship was observed. In the literature, no other studies realized in lymph node metastasis of CRC were found, and similar results were observed by Jansson and Sun [39] on the primary tumour but contradict the other studies analyzed [22, 25, 28-30, 32, 35-40].

In our series, we have not observed association between Ki-67 expression and patient's survival, for CRC $(P=0.321)$ and for lymph node metastasis $(P=0.131)$, series and the same was true when we considered separately colon cancer and rectal cancer. This was corroborated by the observations of Jansson and Sun [39]; however, these findings contradict, in part, the report of Valera et al. [35] that studied primary CRC tumours, and also contradict studies made with lymph node metastasis from breast cancer [43-45] and prostate 
TABLE 4: Assessment of correlation between Ki-67 expression and pathological data.

\begin{tabular}{|c|c|c|c|c|c|c|}
\hline \multirow{2}{*}{ 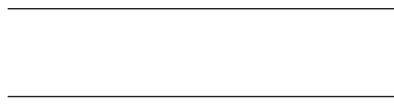 } & \multicolumn{3}{|c|}{$\mathrm{Ki}-67$ in $\mathrm{CRC}$} & \multicolumn{3}{|c|}{ Ki-67 in lymph node metastasis } \\
\hline & $n$ & Positive $n(\%)$ & $P$ & $n$ & Positive $n(\%)$ & $P$ \\
\hline \multicolumn{7}{|l|}{ Tumor size } \\
\hline$\leq 4.5 \mathrm{~cm}$ & 279 & $190(68.1)$ & \multirow{2}{*}{0.519} & 65 & $39(60.0)$ & \multirow{2}{*}{0.211} \\
\hline$>4.5 \mathrm{~cm}$ & 179 & $127(70.9)$ & & 40 & $19(47.5)$ & \\
\hline \multicolumn{7}{|l|}{ Histological type } \\
\hline Adenocarcinoma & 409 & $281(68.7)$ & \multirow{4}{*}{0.665} & 88 & $46(52.3)$ & \multirow{4}{*}{0.483} \\
\hline Mucinous adenocarcinoma & 50 & $32(64.0)$ & & 13 & $8(61.5)$ & \\
\hline Invasive adenocarcinoma & 24 & $18(75.0)$ & & 6 & $4(66.7)$ & \\
\hline Signet ring and mucinous & 4 & $2(50.0)$ & & 2 & $2(100.0)$ & \\
\hline \multicolumn{7}{|l|}{ Differentiation } \\
\hline Well differentiated & 209 & $135(64.6)$ & \multirow{4}{*}{0.049} & 38 & $19(50.0)$ & \multirow{4}{*}{0.670} \\
\hline Moderately differentiated & 208 & $146(70.2)$ & & 46 & $26(56.5)$ & \\
\hline Poorly differentiated & 47 & $40(85.1)$ & & 23 & $14(60.9)$ & \\
\hline Undifferentiated & 4 & $3(75.0)$ & & 1 & $1(100.0)$ & \\
\hline \multicolumn{7}{|l|}{ Tumour penetration } \\
\hline pT1 & 34 & $23(79.3)$ & \multirow{4}{*}{0.013} & 2 & $2(100.0)$ & \multirow{4}{*}{0.553} \\
\hline pT2 & 57 & $39(68.4)$ & & 4 & $2(50.0)$ & \\
\hline pT3 & 370 & $252(68.1)$ & & 96 & $53(55.2)$ & \\
\hline pT4 & 26 & $19(73.1)$ & & 7 & $3(42.9)$ & \\
\hline \multicolumn{7}{|l|}{ Spread to lymph nodes } \\
\hline Absent & 275 & $188(68.4)$ & \multirow{2}{*}{0.940} & 9 & $5(55.6)$ & \multirow{2}{*}{$1.000^{*}$} \\
\hline Present & 198 & $136(68.7)$ & & 89 & $50(56.2)$ & \\
\hline \multicolumn{7}{|l|}{ Venous vessel invasion } \\
\hline Absent & 264 & $179(67.8)$ & \multirow{2}{*}{0.511} & 29 & $13(44.8)$ & \multirow{2}{*}{0.110} \\
\hline Present & 201 & $142(70.4)$ & & 74 & $46(62.2)$ & \\
\hline \multicolumn{7}{|l|}{ TNM } \\
\hline Stage I & 75 & $54(72.0)$ & \multirow{4}{*}{0.425} & & & \\
\hline Stage II & 181 & $121(66.9)$ & & & & \multirow{3}{*}{0.978} \\
\hline Stage III & 152 & $108(71.1)$ & & 78 & $43(55.1)$ & \\
\hline Stage IV & 70 & $45(64.3)$ & & 31 & $17(54.8)$ & \\
\hline
\end{tabular}

${ }^{*}$ Comparisons were examined for statistical significance using Fisher's exact test (when $\left.n \leq 5\right)$.

TABLE 5: Survival analysis: frequency and relative frequency for overall survival and medium of time to death.

\begin{tabular}{lccccc}
\hline Ki-67 & Tissue & $n$ & $\begin{array}{c}\text { Deaths } \\
n(\%)\end{array}$ & $\begin{array}{c}\text { Median for survival time } \\
\text { [95\% confidence interval] }\end{array}$ & Log-rank test $P$ \\
\hline Negative & CRC & 154 & $53(65.6)$ & $65.00[59.49-70.52]$ & 0.321 \\
Positive & & 332 & $125(62.3)$ & $62.09[58.06-66.12]$ & 0.131 \\
\hline Negative & Lymph node & 49 & $17(65.3)$ & $63.48[53.18-73.79]$ & \\
Positive & & 62 & $30(51.6)$ & $50.07[41.06-59.08]$ & \\
\hline
\end{tabular}

TABLE 6: Comparison between Ki-67 index in primary tumor and respective lymph node metastasis.

\begin{tabular}{lccc}
\hline Ki-67 index in CRC & & Ki-67 index in lymph node & Positive \\
Negative & Negative & 12 & $28(26.4)$ \\
Positive & 16 & 49 & $78(73.6)$ \\
\hline Total $n(\%)$ & 29 & $51(57.5)$ & $106(100)$ \\
\hline
\end{tabular}

Comparisons were examined for statistical significance using McNemar test. 


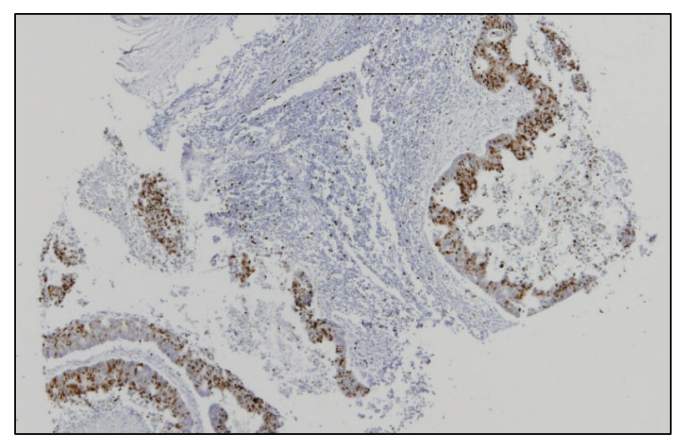

(a)

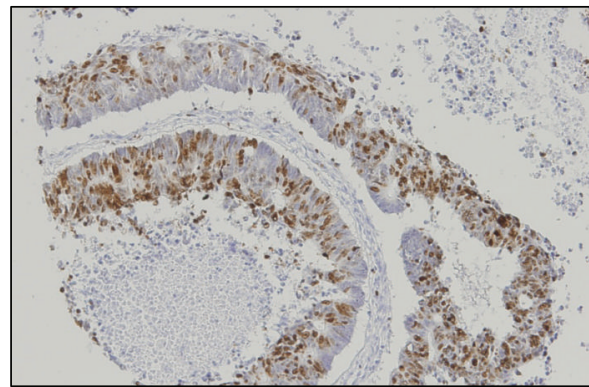

(b)

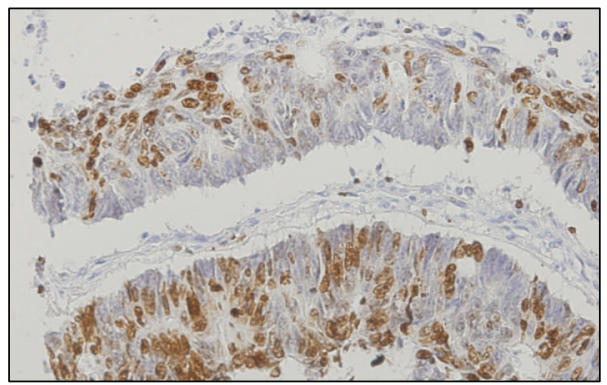

Ki-67 index $\geq 5 \%$

(c)



(d)

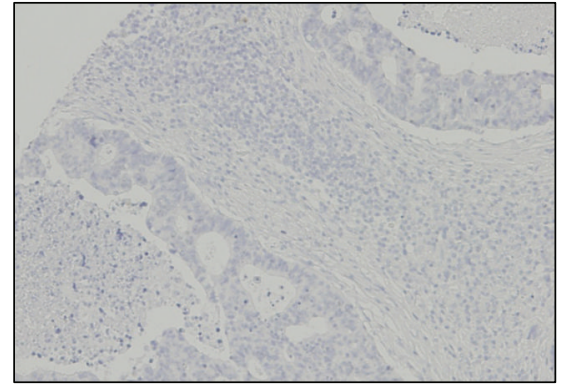

(e)

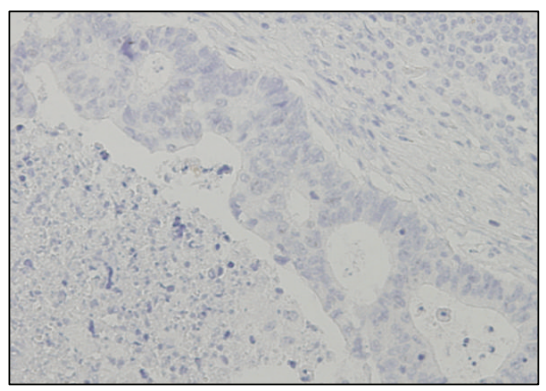

Ki-67 index $=0 \%$

(f)

FIGURE 3: Immunohistochemical expression of Ki-67 in CRC lymph node metastasis samples: ((a) and (d)) original magnification $\times 40$; ((b) and (e)) original magnification $\times 100$; ((c) and (f)) original magnification $\times 200$.

cancer [51], where a higher ki-67 index was associated with a worse patient survival.

Finally, we found association $(P=0.012)$ between Ki67 index in primary tumour and the respective lymph node metastasis and also observed that Ki-67 index was more often positive in the primary tumour than in the respective lymph node metastasis. This result is consistent with the study carried out by Yamauchi et al. [41] to compare Ki67 index in CRC primary tumour and respective nodules of peritoneal dissemination, which, as in the present study, present a greater proportion of proliferating cells in the primary tumour than in the nodules of peritoneal dissemination, not advancing; however, there is no explanation for this finding. Distinct results were observed for similar studies realized in breast cancer [42-44], where lymph node metastasis presents higher ki-67 index than primary tumour, but also no explanation was mentioned. Recently, Jo and colleagues have found a significant difference of higher Ki-67 proliferation in nodal metastasis and primary gastric cancer [52]. Most of the criticism of Ki-67 evaluation is related to the differences of antibodies, slide background, retrieval protocols applied in preparing the immunoreaction, and the scores used to evaluate the significance of $\mathrm{Ki}-67$ proliferation rates. This concern is pertinent and most of the works that evaluate this premise did not reach a consensus. Interesting, automated evaluation of the Ki-67 labelled preparation has been adjudicated as superior than manual analyses. Moreover, subdividing the cases in low and high proliferative rate improve the kappa correlation. Besides these advisements, the lack of standard protocols among the laboratories limits the clinical relevance of the works [53].

This difference between Ki-67 index in primary CRC tumour and respective lymph node metastasis may explain the absence of correlation with clinicopathological data 

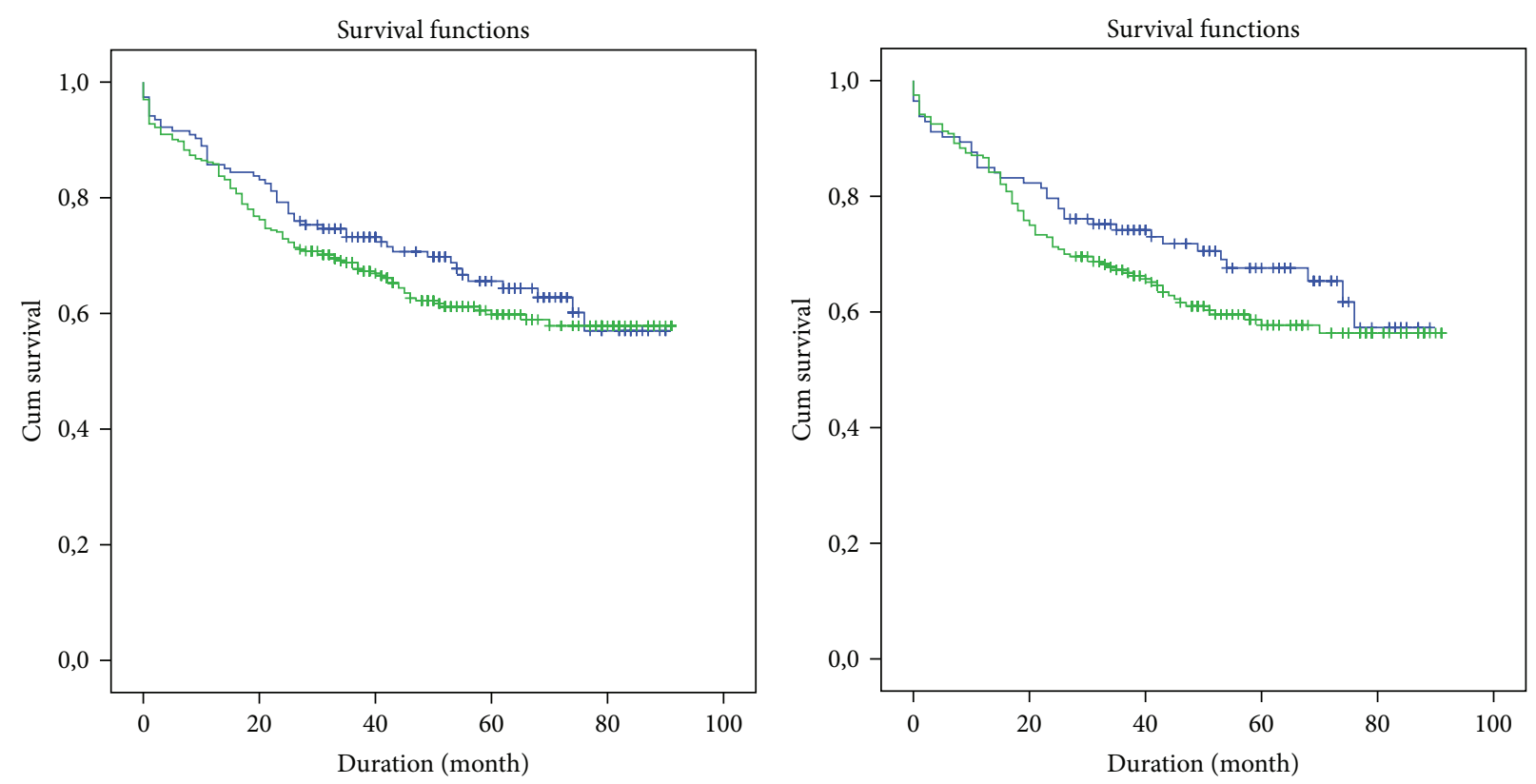

Ki67_CRC

Ki67_CRC

$\begin{array}{ll}\neg \text { Negative } & + \text { Negative-censored } \\ \neg \text { Positive } & + \text { Positive-censored }\end{array}$

$\begin{array}{ll}\neg \text { Negative } & + \text { Negative-censored } \\ \neg \text { Positive } & + \text { Positive-censored }\end{array}$

(a)

(b)

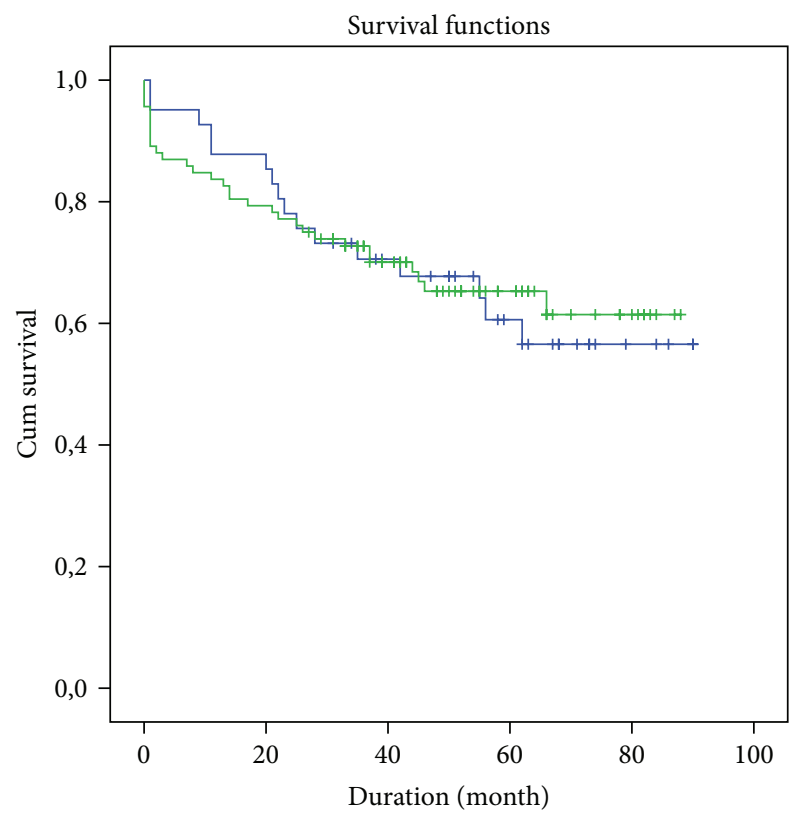

Ki67_CRC

$\begin{array}{ll}\neg \text { Negative } & + \text { Negative-censored } \\ \neg \text { Positive } & + \text { Positive-censored }\end{array}$

(c)

FIGURE 4: Survival curve of patients with CRC according to Ki-67, assessed by the log-rank test: (a) colorectal cancer: $P=0.321$; (b) colon cancer: $P=0.213$; (c) rectal cancer: $P=0.874$. 




Ki_lymph node

$\begin{array}{ll}\neg<5 & +<5 \text {-censored } \\ \neg \geq 5 & +\geq 5 \text {-censored }\end{array}$

(a)

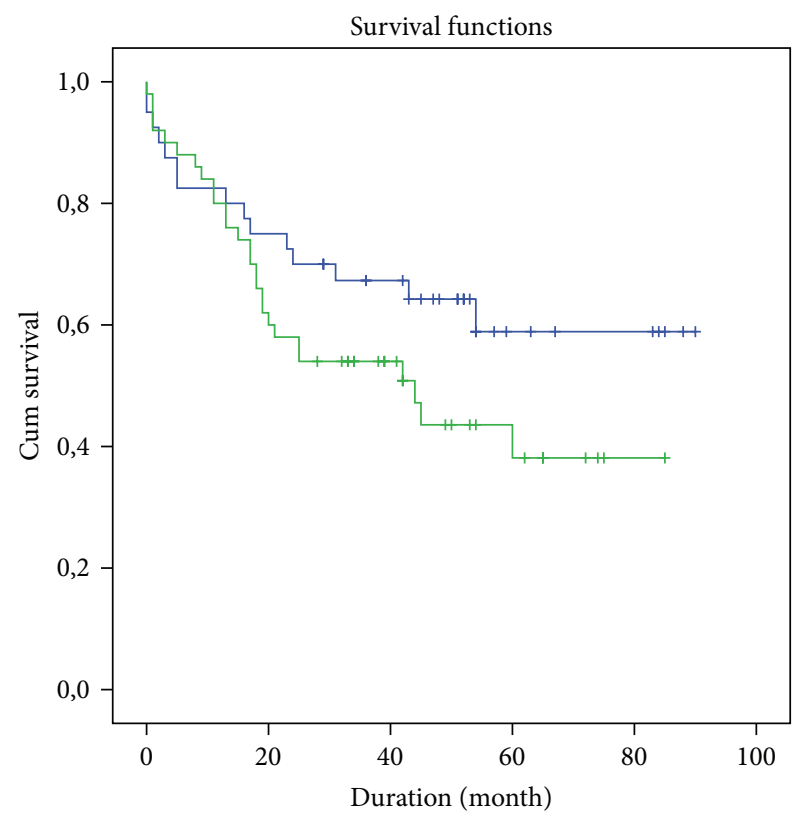

Ki_lymph node

$\begin{array}{ll}\neg<5 & +<5 \text {-censored } \\ \neg \geq 5 & +\geq 5 \text {-censored }\end{array}$

(b)

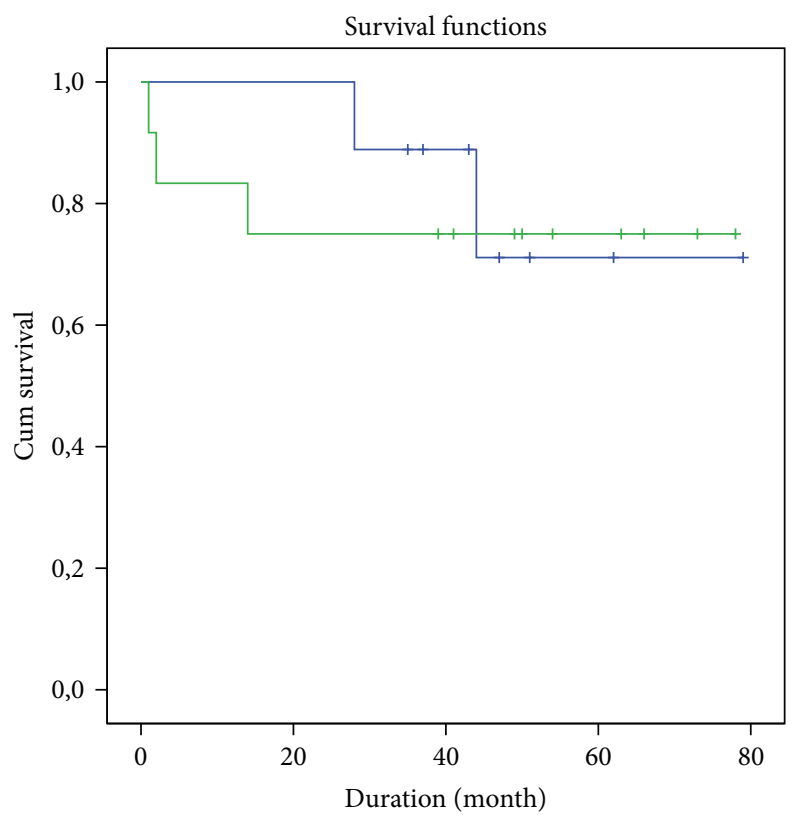

Ki_lymph node

$\begin{array}{ll}\neg<5 & +<5 \text {-censored } \\ \neg \geq 5 & +\geq 5 \text {-censored }\end{array}$

(c)

FIGURE 5: Survival curve of patients with CRC lymph node metastasis according to Ki-67, assessed by the log-rank test: (a) colorectal cancer: $P=0.131$; (b) colon cancer: $P=0.127$; (c) rectal cancer: $P=0.809$. 


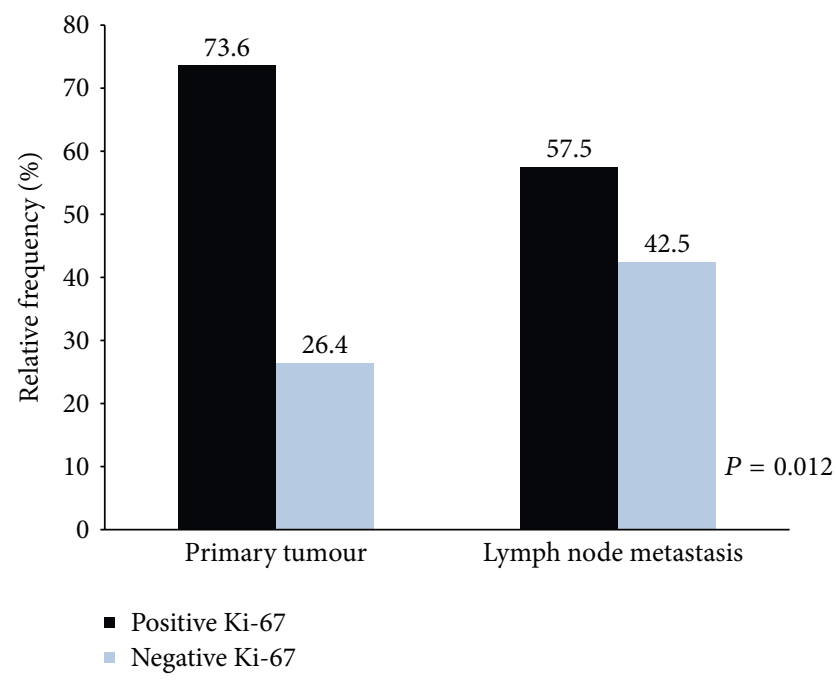

FIGURE 6: Graphic representation of Ki-67 index in primary CRC tumour and respective lymph node metastasis.

and survival observed in this study as it shows that the proliferative profile of the primary CRC tumour is different from that of its metastasis. One possible explanation for the low proliferative index of lymph node metastasis as compared to primary tumour is that lymph node cannot represent an optimal proliferative environment, since it is known that nutrient and oxygen deprivation induces cell cycle arrest, leading to a decreased proliferation rate [54]. Another possible explanation may be due to of Ki-67 own usage as a marker of cell proliferation, since Ki-67 expression seems to be influenced by nutrient intake of the cell [48].

The smaller number of patients with a positive Ki-67 index in lymph node metastasis can also contribute to the poor prognosis attributed to the presence of lymph node metastasis $[32,50,55,56]$ in CCR, since most antineoplastic agents target proliferating cells, cells with a low proliferation rate are more resistant to such treatment [53], and this hypothesis was also stated by Cabibi et al. [44], relatively to the subgroup of patients with breast cancer and lower ki-67 index in lymph node metastasis than in primary tumour.

\section{Conclusions}

In this study, we evaluated the immunohistochemical expression of Ki-67 in CRC and respective lymph node metastasis and simultaneously try to determine its correlation with clinicopathological data and patient survival. From the results obtained, it was found that this protein has higher expression in tumour tissue, supporting the hypothesis of involvement of $\mathrm{Ki}-67$ in CRC and its role as a proliferative marker. Furthermore, in CRC samples, the association between the expression of this protein and the degree of tumour differentiation and penetration was found which enables Ki-67 to be used as a potential prognostic factor in CRC.

Although we have not obtained statistical significant results for lymph node metastasis series we observed a statistically significant difference between the Ki-67 index of the primary tumour and the respective lymph node metastasis, which is more often positive in the primary tumour. These results show that lymph node metastasis is composed of proliferating cells slower than that present in the primary tumour and it is hypothesized that the lymph node might not constitute an optimal environment for tumour cells proliferation or that $\mathrm{Ki}-67$ might not be the more suitable proliferative marker for use in lymph node metastasis. This result also raises the possibility that tumour cells in lymph nodes can be more resistant to chemotherapy treatments, thus contributing to the poor prognosis of these patients.

\section{Conflict of Interests}

The authors declare that they have no conflict of interests.

\section{References}

[1] S. Svagzdys, V. Lesauskaite, D. Pavalkis, I. Nedzelskiene, D. Pranys, and A. Tamelis, "Microvessel density as new prognostic marker after radiotherapy in rectal cancer," BMC Cancer, vol. 9, article 95, 2009.

[2] G. Des Guetz, B. Uzzan, P. Nicolas et al., "Microvessel density and VEGF expression are prognostic factors in colorectal cancer. Meta-analysis of the literature," British Journal of Cancer, vol. 94, no. 12, pp. 1823-1832, 2006.

[3] H. Brenner, M. Hoffmeister, and U. Haug, "Should colorectal cancer screening start at the same age in European countries? Contributions from descriptive epidemiology," British Journal of Cancer, vol. 99, no. 3, pp. 532-535, 2008.

[4] S. F. Martins, R. M. Reis, A. M. Rodrigues, F. Baltazar, and A. Filho, "Role of endoglin and VEGF family expression in colorectal cancer prognosis and anti-angiogenic therapies," World Journal of Clinical Oncology, vol. 2, no. 6, pp. 272-280, 2011.

[5] S. F. Martins, E. A. Garcia, M. A. M. Luz, F. Pardal, M. Rodrigues, and A. L. Filho, "Clinicopathological correlation and prognostic significance of VEGF-A, VEGF-C, VEGFR-2 and VEGFR-3 expression in colorectal cancer," Cancer Genomics \& Proteomics, vol. 10, no. 2, pp. 55-67, 2013.

[6] M. Zavoral, S. Suchanek, F. Zavada et al., "Colorectal cancer screening in Europe," World Journal of Gastroenterology, vol. 15, no. 47, pp. 5907-5915, 2009.

[7] C. Bosetti, F. Levi, V. Rosato et al., "Recent trends in colorectal cancer mortality in Europe," International Journal of Cancer, vol. 129, no. 1, pp. 180-191, 2011.

[8] Roreno, Corpo Humano-Roreno-Registo Oncológico Regional do Norte, http://www.roreno.com.pt/p.

[9] M. Malvezzi, P. Bertuccio, F. Levi, C. La Vecchia, and E. Negri, "European cancer mortality predictions for the year 2013," Annals of Oncology, vol. 24, no. 3, pp. 792-800, 2013.

[10] C. G. Pinto, A. T. Paquete, and I. Pissarra, "Colorectal cancer in Portugal," European Journal of Health Economics, vol. 10, no. 1, pp. S65-S73, 2010.

[11] J. Ferlay, E. Steliarova-Foucher, J. Lortet-Tieulent et al., "Cancer incidence and mortality patterns in Europe: estimates for 40 countries in 2012," European Journal of Cancer, vol. 49, no. 6, pp. 1374-1403, 2013.

[12] S. Gurzu, J. Jung, L. Azamfirei, T. Mezei, A. M. Cîmpean, and Z. Szentirmay, "The angiogenesis in colorectal carcinomas with and without lymph node metastases," Romanian Journal of Morphology and Embryology, vol. 49, no. 2, pp. 149-152, 2008. 
[13] S. Cascinu, V. Georgoulias, D. Kerr, T. Maughan, R. Labianca, and M. Ychou, "Colorectal cancer in the adjuvant setting: perspectives on treatment and the role of prognostic factors," Annals of Oncology, vol. 14, no. 2, pp. 25-29, 2003.

[14] D. D. Alexander, J. Waterbor, T. Hughes, E. Funkhouser, W. Grizzle, and U. Manne, "African-American and Caucasian disparities in colorectal cancer mortality and survival by data source: an epidemiologic review," Cancer Biomarkers, vol. 3, no. 6, pp. 301-313, 2007.

[15] H. J. Calvo, G. D. Ortega, R. J. M. Pardo, M. A. J. López, and T. Cubo, "Biologia molecular del processo metastásico del cancer colorectal," Cirugia Española, vol. 68, pp. 577-587, 2000.

[16] S. Y. Zafar, A. P. Abernethy, D. H. Abbott et al., "Comorbidity, age, race and stage at diagnosis in colorectal cancer: a retrospective, parallel analysis of two health systems," BMC Cancer, vol. 8, article 345, 2008.

[17] L. A. G. Ries, P. A. Wingo, D. S. Miller et al., “The annual report to the nation on the status of cancer, 1973-1997, with a special section on colorectal cancer," Cancer, vol. 88, no. 10, pp. 23982424, 2000.

[18] R. S. Saad, Y. L. Liu, G. Nathan, J. Celebrezze, D. Medich, and J. F. Silverman, "Endoglin (CD105) and vascular endothelial growth factor as prognostic markers in colorectal cancer," Modern Pathology, vol. 17, no. 2, pp. 197-203, 2004.

[19] C. Barozzi, M. Ravaioli, A. D’Errico et al., "Relevance of biologic markers in colorectal carcinoma: a comparative study of a broad panel," Cancer, vol. 94, no. 3, pp. 647-657, 2002.

[20] A. J. Bilchik, M. DiNome, S. Saha et al., "Prospective multicenter trial of staging adequacy in colon cancer: preliminary results," Archives of Surgery, vol. 141, no. 6, pp. 527-533, 2006.

[21] T. Scholzen and J. Gerdes, “The Ki-67 protein: from the known and the unknown," Journal of Cellular Physiology, vol. 182, no. 3, pp. 311-322, 2000.

[22] K. Guzinska-Ustymowicz, E. Stepien, and A. Kemona, "MCM2, Ki-67 and PCNA protein expressions in pT3G2 colorectal cancer indicated lymph node involvement," Anticancer Research, vol. 28, no. 1, pp. 451-457, 2008.

[23] D. Freitas, M. H. Goulão, E. Camacho et al., "Clinical relevance of proliferation biomarkers and p53 expression in rectal mucosa and sporadic colonic adenomas: a prospective study," HepatoGastroenterology, vol. 49, no. 47, pp. 1269-1274, 2002.

[24] H. A. Saleh, H. Jackson, G. Khatib, and M. Banerjee, "Correlation of bcl-2 oncoprotein immunohistochemical expression with proliferation index and histopathologic parameters in colorectal neoplasia," Pathology \& Oncology Research, vol. 5, no. 4, pp. 273-279, 1999.

[25] M. X. Lin, Z.-F. Wen, Z.-Y. Feng, and D. He, "Expression and significance of Bmi-1 and Ki67 in colorectal carcinoma tissues," Ai Zheng, vol. 27, no. 12, pp. 1321-1326, 2008.

[26] P. Dziegiel, J. Forgacz, E. Suder, P. Surowiak, J. Kornafel, and M. Zabel, "Prognostic significance of metallothionein expression in correlation with Ki-67 expression in adenocarcinomas of large intestine," Histology and Histopathology, vol. 18, no. 2, pp. 401-407, 2003.

[27] X. Z. Bai, J. R. W. Masters, N. O'Donoghue et al., "Prognostic markers in clinically localised prostate cancer," International Journal of Oncology, vol. 14, no. 4, pp. 785-791, 1999.

[28] W. X. Gao, J. G. Feng, Y. F. Yang et al., "PCNA in colorectal carcinoma and the prognosis," Xian Dai Yu Fang Yi Xue, vol. 2, no. 34, pp. 225-229, 2007.
[29] M. Micev, M. Micev-Cosić, V. Todorović et al., "Histopathology of residual rectal carcinoma following preoperative radiochemotherapy," Acta Chirurgica Iugoslavica, vol. 51, no. 2, pp. 99-108, 2004.

[30] F. L. Nussrat, H. H. Ali, H. G. Hussein, and R. J. Al-Ukashi, "Immunohistochemical expression of ki-67 and p53 in colorectal adenomas: a clinicopathological study," Oman Medical Journal, vol. 26, no. 4, pp. 229-234, 2011.

[31] S. Toru and B. Bilezikçi, "Early changes in carcinogenesis of colorectal adenomas," West Indian Medical Journal, vol. 61, no. 1, pp. 10-16, 2012.

[32] Y. Hashimoto, M. Skacel, I. C. Lavery, A. L. Mukherjee, G. Casey, and J. C. Adams, "Prognostic significance of fascin expression in advanced colorectal cancer: an immunohistochemical study of colorectal adenomas and adenocarcinomas," BMC Cancer, vol. 6, article 241, 2006.

[33] C. T. F. Oshima, K. Iriya, and N. M. Forones, "Ki-67 as a prognostic marker in colorectal cancer but not in gastric cancer," Neoplasma, vol. 52, no. 5, pp. 420-424, 2005.

[34] C. Evans, I. Morrison, A. G. Heriot et al., "The correlation between colorectal cancer rates of proliferation and apoptosis and systemic levels plus their influence upon survival," British Journal of Cancer, vol. 94, no. 10, pp. 1412-1419, 2006.

[35] V. Valera, N. Yokoyama, B. Walter, H. Okamoto, T. Suda, and K. Hatakeyama, "Clinical significance of Ki-67 proliferation index in disease progression and prognosis of patients with resected colorectal carcinoma," British Journal of Surgery, vol. 92, no. 8, pp. 1002-1007, 2005.

[36] H. L. De Menezes, M. J. Jucá, E. G. D. A. Gomes, B. L. B. B. P. Nunes, H. O. Costa, and D. Matos, "Analysis of the immunohistochemical expressions of p53, bcl-2 and Ki-67 in colorectal adenocarcinoma and their correlations with the prognostic factors," Arquivos de Gastroenterologia, vol. 47, no. 2, pp. 141-147, 2010.

[37] C. Ghiţă, I. D. Vîlcea, M. Dumitrescu et al., “The prognostic value of the immunohistochemical aspects of tumor suppressor genes p53, bcl-2, PTEN and nuclear proliferative antigen Ki67 in resected colorectal carcinoma," Romanian Journal of Morphology and Embryology, vol. 53, no. 3, pp. 549-556, 2012.

[38] U. Nabi, A. H. Nagi, and W. Sami, "Ki-67 proliferating index and histological grade, type and stage of colorectal carcinoma," Journal of Ayub Medical College, Abbottabad, vol. 20, no. 4, pp. 44-48, 2008.

[39] A. Jansson and X.-F. Sun, "Ki-67 expression in relation to clinicopathological variables and prognosis in colorectal adenocarcinomas," APMIS, vol. 105, no. 9, pp. 730-734, 1997.

[40] C. J. Allegra, S. Paik, L. H. Colangelo et al., "Prognostic value of thymidylate synthase, Ki-67, and p53 in patients with Dukes' $\mathrm{B}$ and $\mathrm{C}$ colon cancer: a National Cancer Institute-National Surgical Adjuvant Breast and Bowel Project collaborative study," Journal of Clinical Oncology, vol. 21, no. 2, pp. 241-250, 2003.

[41] H. Yamauchi, T. Suto, W. Kigure et al., “The progression potential of peritoneal dissemination nodules from gastrointestinal tumors," International Surgery, vol. 96, no. 4, pp. 352-357, 2011.

[42] F. Buxant, V. Anaf, P. Simon, I. Fayt, and J. C. Noël, "Ki-67 immunostaining activity is higher in positive axillary lymph nodes than in the primary breast tumor," Breast Cancer Research and Treatment, vol. 75, no. 1, pp. 1-3, 2002.

[43] D. Park, R. Kåresen, T. Noren, and T. Sauer, "Ki-67 expression in primary breast carcinomas and their axillary lymph node metastases: clinical implications," Virchows Archiv, vol. 451, no. 1, pp. 11-18, 2007. 
[44] D. Cabibi, V. Mustacchio, A. Martorana et al., "Lymph node metastases displaying lower Ki-67 immunostaining activity than the primary breast cancer," Anticancer Research, vol. 26, no. 6B, pp. 4357-4360, 2006.

[45] K. Tawfik, B. F. Kimler, M. K. Davis, F. Fan, and O. Tawfik, "Ki-67 expression in axillary lymph node metastases in breast cancer is prognostically significant," Human Pathology, vol. 44, no. 1, pp. 39-46, 2013.

[46] F. L. Greene, D. L. Page, I. D. Fleming et al., Eds., AJCC Cancer Staging Manual, Springer, New York, NY, USA, 6th edition, 2002.

[47] C. Pinheiro, A. Longatto-Filho, C. Scapulatempo et al., "Increased expression of monocarboxylate transporters 1, 2, and 4 in colorectal carcinomas," Virchows Archiv, vol. 452, no. 2, pp. 139-146, 2008.

[48] D. C. Brown and K. C. Gatter, "Monoclonal antibody Ki-67: its use in histopathology," Histopathology, vol. 17, no. 6, pp. 489503, 1990.

[49] J. Gerdes, U. Schwab, H. Lemke, and H. Stein, "Production of a mouse monoclonal antibody reactive with a human nuclear antigen associated with cell proliferation," International Journal of Cancer, vol. 31, no. 1, pp. 13-20, 1983.

[50] Y. Kubota, R. E. Petras, K. A. Easley, T. W. Bauer, R. R. Tubbs, and V. W. Fazio, "Ki-67-determined growth fraction versus standard staging and grading parameters in colorectal carcinoma: a multivariate analysis," Cancer, vol. 70, no. 11, pp. 2602-2609, 1992.

[51] M. Hosaka, Y. Takano, M. Iki, and et al, "Prognostic significance of Ki-67, p53, and Bcl-2 expression in prostate cancer patients with lymph node metastases: a retrospective immunohistochemical analysis," Pathology International, vol. 48, no. 1, pp. 4146, 1998.

[52] M. J. Jo, J. Y. Park, J. S. Song et al., "Biopathologic features and clinical significance of micrometatasis in the lymph node of early gastric cancer," World Journal of Gastroenterology, vol. 21, no. 2, pp. 667-674, 2015.

[53] J. Harvey, C. Thomas, B. Wood et al., "Practical issues concerning the implementation of Ki-67 proliferative index measurement in breast cancer reporting," Pathology, vol. 47, no. 1, pp. 13-20, 2015.

[54] O. Trédan, C. M. Galmarini, K. Patel, and I. F. Tannock, "Drug resistance and the solid tumor microenvironment," Journal of the National Cancer Institute, vol. 99, no. 19, pp. 1441-1454, 2007.

[55] D. L. Longo, A. S. Fauci, D. L. Kasper, S. L. Hauser, J. L. Jameson, and J. Loscalzo, Eds., Harrison's Principles of Internal Medicine, McGraw-Hill, New York, NY, USA, 18th edition, 2012.

[56] T. E. Le Voyer, E. R. Sigurdson, A. L. Hanlon et al., "Colon cancer survival is associated with increasing number of lymph nodes analyzed: a secondary survey of intergroup trial INT0089," Journal of Clinical Oncology, vol. 21, no. 15, pp. 2912-2919, 2003. 


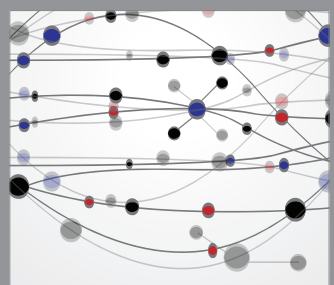

The Scientific World Journal


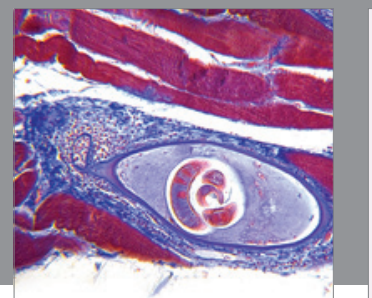

Gastroenterology

Research and Practice
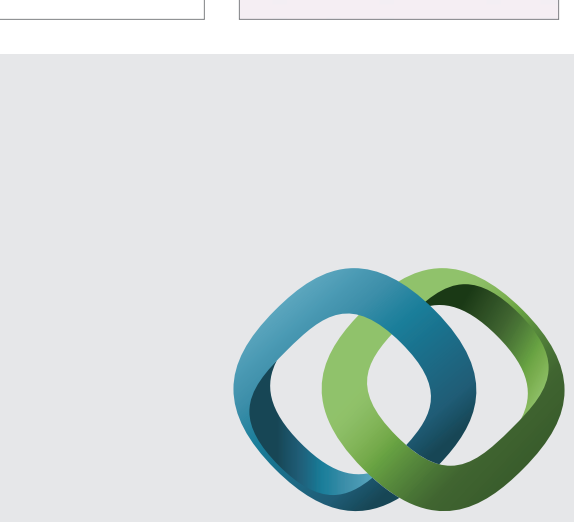

\section{Hindawi}

Submit your manuscripts at

http://www.hindawi.com
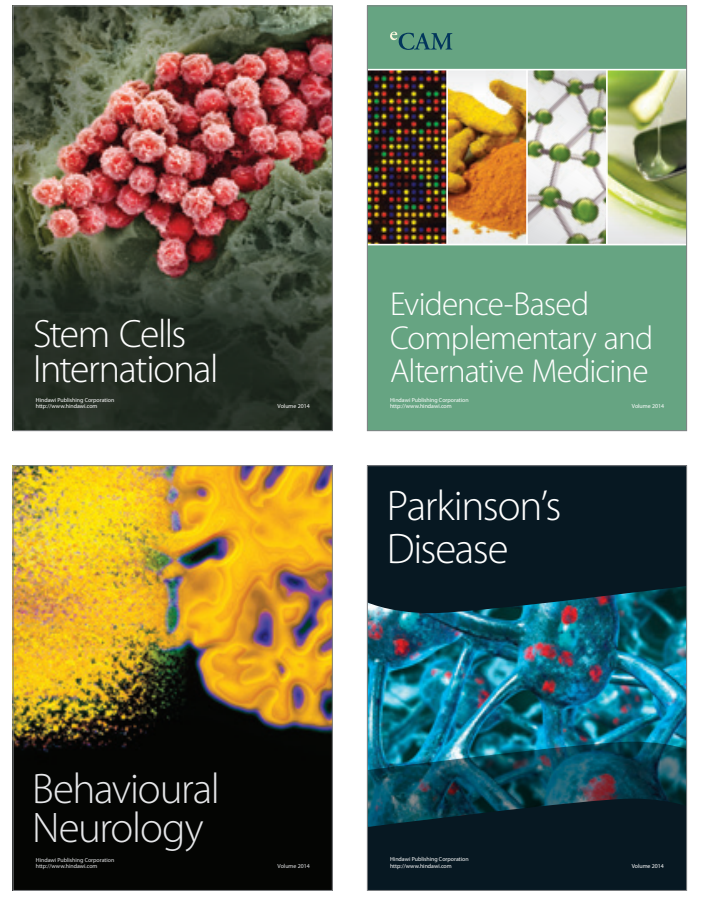
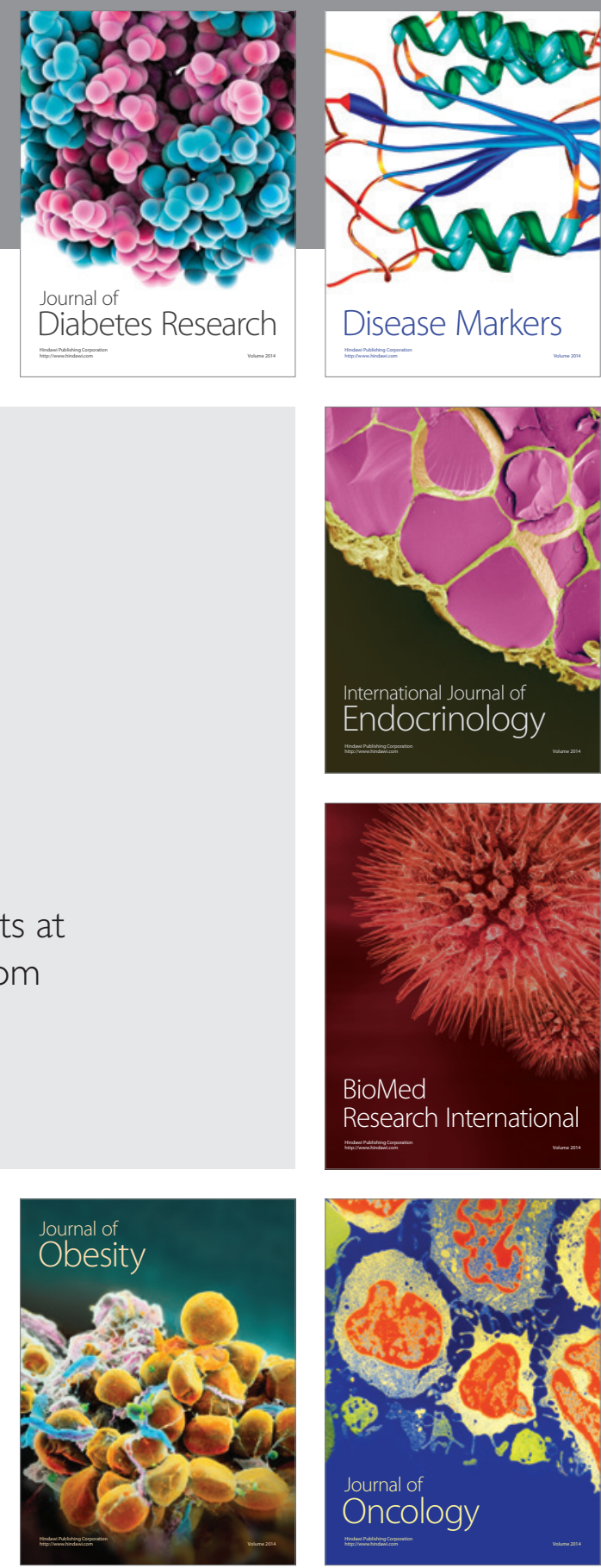

Disease Markers
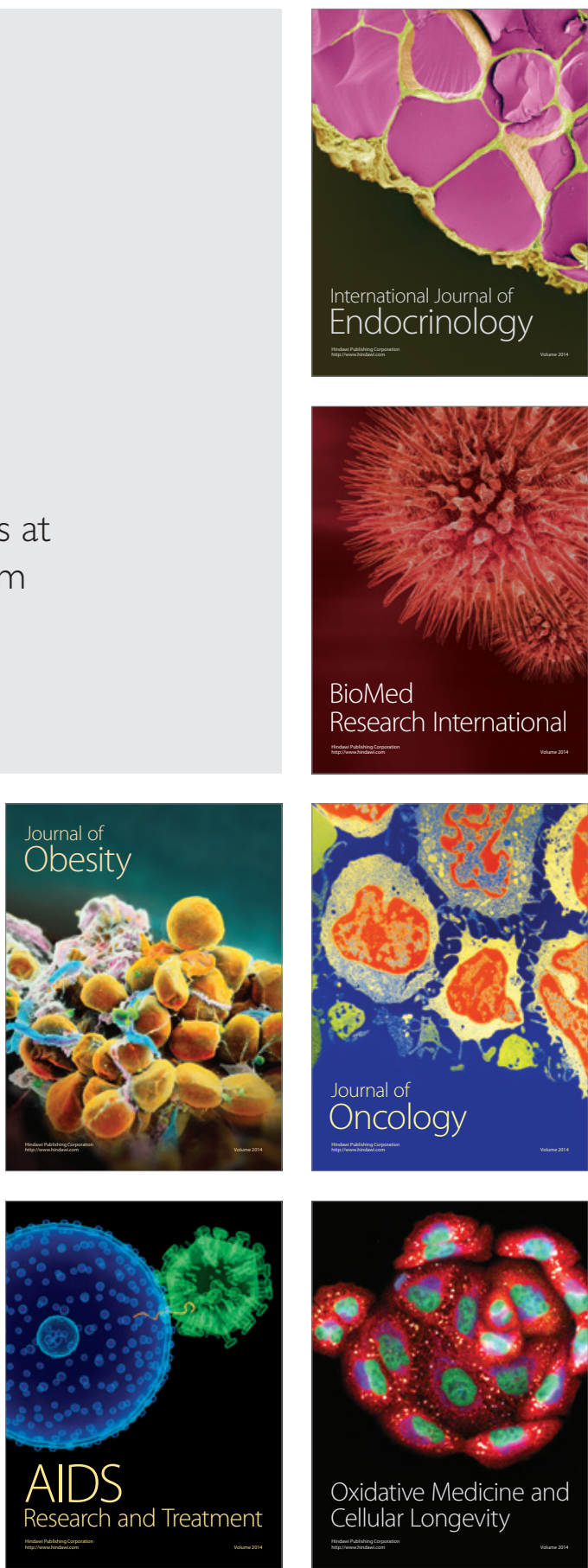